the Milne seismograph by Messrs. J. J. Shaw and J. H. Burgess.

The meeting concluded on Friday afternoon with a very interesting address by Prof. Pierre Weiss on new views of magnetism, in which he described his researches on the part played by the magneton, or definite unit of magnetism, in the phenomena of iron, nickel, cobalt, and their alloys.

\section{THE BRITISH ASSOCIATION. SECTION K} BOTANY.

Opening Address ${ }^{1}$ by Prof. W. H. Lang, F.R.S., President OF the Section.

Phyletic and Causal Morphology.

I PROPOSE to deal with some aspects of the study of plant-morphology. In doing so I shall not accept any definition of morphology that would separate it artificially from other departments of botany. I regard the aim of plant-morphology as the study and scientific explanation of the form, structure, and development of plants. This abandons any sharp separation of morphology and physiology, and claims for morphology a wider scope than has been customary for the past fifty years. During this period the problem of morphology has been recognised as being "a purely historical one," "perfectly distinct from any of the questions with which physiology has to do," its aim being "to reconstruct the evolutionary tree." The limitation of the purpose of morphological study, expressed in these phrases from the admirable addresses delivered to this section by $\mathrm{Dr}$. Scott and Prof. Bower some twenty years ago, was due to the influence of the theory of descent. I fully recognise the interest of the phyletic ideal, but am unable to regard it as the exclusive, or perhaps as the most important, object of morphological investigation. To accept the limitation of morphology to genealogical problems is inconsistent with the progress of this branch of study before the acceptance of the theory of descent, and leaves out many of the most important problems that were raised and studied by the earlier morphologists.

In the history of morphology, after it had ceased to be the handmaid of the systematic botany of the higher plants, we may broadly distinguish an idealistic period, a developmental period, and a phyletic period. The period of developmental morphology, the most fruitful and the most purely inductive in our science, was characterised by an intimate connection between morphological and physiological work. Among its contributions were studies of development or "growth histories" of whole plants and their members. These were carried out, in part at least, in order to investigate the nature of development, and such general problems found their expression at the close of the period in the "Allgemeine Morphologie" of Hofmeister. The "Origin of Species" took some years before it affected the methods and aims of botanical work. Then its effect on morpho$\operatorname{logy}$ was revolutionary, and, as in all revolutions, some of the best elements of the previous régime were temporarily obscured. This excessive influence of the theory of descent upon morphology did not come from Darwin himself, but from his apostle Haeckel, who gave a very precise expression to the idea of a genealogical grouping of animals and plants, illustrated by elaborate hypothetical phylogenetic trees. Such ideas rapidly dominated morphological work, and we find a special "phylogenetic method" advo- cated by Strasburger. The persistence of the phyletic period to the present time is shown, not only in the devotion of morphology to questions of relationship, but in the attempts made to base homologies upon descent only. Lankester's idea of homogeny can be traced to the influence of Haeckel, and nothing shows the consistency of phyletic morphology to its clear but somewhat narrow ideal so plainly as the repeated attempts to introduce into practice a sharp distinction between hom $g$ nny and homoplasy.

Prof. Bower, in his address last year and in other papers, has dealt illuminatingly with the aims and methods of phyletic morphology. I need only direct attention to some aspects of the present position of this, which bear on causal morphology. The goal of phyletic morphology has throughout been to construct the genealogical tree of the vegetable kingdom. In some ways this seems farther off than ever. Phyletic work has been its own critic, and the phylogeny of the genealogical tree, since that first very complete monophyletic one by Haeckel, affords a clear exampie of a reduction series. The most recent and trustworthy graphic representations of the inter-relationships of plants look more like a bundle of sticks than a tree. Consider for a moment our complete ignorance of the inter-relationships of the Algx, Bryophyta, and Pteridophyta. Regarding the Algæ we have no direct evidence, but the comparative study of existing forms has suggested parallel developments along four or more main lines from different startingpoints in a very simple unicellular ancestry. We have no clue, direct or indirect, to the ancestral forms of the Bryophyta, and it is an open question whether there may not be as many parallel series in this group as in the Algæ. The Pteridophyta seem a better case, for we have direct evidence from fossil plants as well as the comparison of living forms to assist us. Though palæobotany has added the Sphenophyllales to the existing groups of vascular cryptogams and has greatly enlarged our conceptions of the.others, there is no proof of how the great groups are related to one another. As in the Bryophyta, they may represent several completely independent parallel lines. There is no evidence as to what sort of plants the Pteridophyta were derived from, and in particular none that relates them to any group of Bryophyta or Algæ. I do not want to labour the argument, but much the same can be said of the seed-plants, though there is considerable evidence and fairly general agreement as to some Gymnosperms having come from ancient Filicales. The progress of phyletic work has thus brought into relief the limitations of the possible results and the inherent difficulties. As pointed out by Prof. Bower, we can hope for detailed and definite results only in particularly favourable cases, like that of the Filicales.

The change of attitude shown in recent phyletic work towards "parallel developments in phyla which are believed to have been of distinct origin " is even more significant. Prof. Bower spoke of the prevalence of this as an "obstacle to success," and so it is if our aim is purely phyletic. In another way the demonstration of parallel developments constitutes a positive result of great value. Thus Prof. Bower's own work has led to the recognition of a number of series leading from the lower to the higher Filicales. By independent but parallel evolutionary paths, from diverse starting-points in the more ancient ferns, such similarity has been reached that systematists have placed the plants of distinct origin in the same genus. In these progressions a number of characters run more or less clearly parallel, so that the final result appears to be due "to a phyletic drift that may have affected similarly a plurality of lines of descent." This conclusion, based on detailed investigation, 
appears to me to be of far-reaching importance. If a "phyletic drift" in the ferns has resulted in the independent and parallel origin of such characters as dictyostely, the mixed sorus, and the very definite type of sporangium with a vertical annulus and transverse dehiscence, the case for parallel developments in other groups is greatly strengthened. The interest shifts to the causes underlying such progressive changes as appear in parallel developments, and the problem becomes one of causal morphology rather than purely historical.

The study of parallel developments would, indeed, seem likely to throw more light on the morphology of plants than the changes traced in a pure phyletic line, for it leads us to seek for common causes, whether internal or external. We cease to be limited in our comparisons by actual relationship, or forbidden to elucidate the organisation in one group by that which has arisen independently in another. Similarly the prohibition against comparing the one generation in the life-cycle with the other falls to the ground, quite apart from any question of whether the alternation is homologous or antithetic. The methods of advance and the causal factors concerned become the important things, and if, for example, light is thrown on the organisation of the fern-plant by comparison with the gametophyte of the moss, so much the better. This, however, is frankly to abandon phylogeny as "the only real basis of morphological study," and with this any attempt to base homology on homogeny. Many of the homologies that exist between series of parallel development are what have been happily termed homologies of organisation; these are sometimes so close as to result in practical identity, at other times so distinct as to be evident homoplasies. The critical study of homologies of organisation over as wide an area as possible becomes of primary interest and importance.

Since about the beginning of the present century a change of attitude towards morphological problems has become more and more evident in several ways. It seems to be a phyletic drift affecting simultaneously a plurality of lines of thought. The increasing tendency to look upon problems of development and construction from a causal point of view is seen in the prominence given to what may be termed developmental physiology, and also in what Goebel has called organography. These deal with the same problems from different sides and neither formulates them as they appear to the morphologist. Together with genetics, they indicate the need of recognising what I prefer to call general or causal morphology.

The problems of causal morphology are not new, though most of them are still unsolved and are difficult to formulate, let alone to answer As we have seen, they were recognised in the time of developmental morphology, though they have since been almost wholly neglected by morphologists. So far as they have been studied during the phyletic period, it has been from the physiological rather than the morphological side. Still, such problems force themselves upon the ordinary morphologist, and it is from his position that I venture to approach them. I willingly recognise, however, that causal morphology may also be regarded as a department of plantphysiology. In development, which is the essential of the problem, the distinction between morphology and physiology really disappears, even if this distinction can be usefully maintained in the study of the fully developed organism. We are brought up against a fact which is readily overlooked in these days of specialisation, that botany is the scientific study of plants.

General morphology agrees with physiology in its aim, being a causal explanation of the plant and not NO. 2400 , VOL. 96$]$ historical. Its problems would remain if the phyletic history were before us in full. In the present state of our ignorance, however, we need not be limited to a physico-chemical explanation of the plant. Modern physiology rightly aims at this so far as possible, but, while successful in some departments, has to adopt other methods of explanation and analysis in dealing with irritability. It is even more obvious that no physico-chemical explanation extends far enough to reach the problems of development and morphological construction. 'The morphologist must therefore take the complicated form and its genesis in development and strive for a morphological analysis of the developing plant. This is to attack the problem from the other side, and to work back from the phenomena of organisation toward concepts of the nature of the underlying substance.

It is to these questions of general morphology with a causal aim (for causal morphology, though convenient, is really too ambitious a name for anything we yet possess) that $I$ wish to ask your attention. All we can do at first is to take up a new attitude towards our problems, and to gather here and there hints upon which new lines of attack may be based. This new attitude is, however, as I have pointed out, a very old one, and in adopting it we re-connect with the period of developmental morphology. Since the limited time at my disposal forbids adequate reference to historical details, and to the work and thought of many botanists in this field, let me in a word disclaim any originality in trying to express in relation to some morphological problems what seems to me the significant trend, in part deliberate and in part unconscious, of morphology at present. The methods available in causal morphology are the detailed study in selected plants of the normal development and its results, comparison over as wide an area as possible, with special attention to the essential correspondences (homologies of organisation) arrived at independently, the study of variations, mutations, and abnormalities in the light of their development, and ultimately critical experimental work. This will be evident in the following attempt to look at some old questions from the causal point of view. I shall take them as suggested by the fern, without confining my remarlss to this. The fern presents all the main problems in the morphology of the vegetative organs of the higher plants, and what little I have to say regarding the further step to the seed-habit will come as a natural appencix to its consideration.

\section{Individual Development.}

Twice in its normal life-history the fern exhibits a process of development starting from the single cell and resulting in the one case in the prothallus and in the other in the fern-plant For the present we may treat these two stages in the life-history as individuals, their development presenting the same general problems as a plant of, say, Fucus or Enteromorpha, where there is no alternation of generations. How is the morphologist to regard this process of individual development?

In the first place, we seem forced to regard the specific distinctness as holding for the germ as well as the resulting mature plant, however the relation between the germ-cell and the characters of the developed organism is to be explained. We start thus with a conception of specific substance, leaving it quite an open question on what the specific nature depends. This enables us to state the problem of development freed from all considerations of the ultimate uses of the developed structure. The course of development to the adult condition can be looked upon as the manifestation of the properties of the specific substance under certain conditions. This 
decides our attitude as morphologists to the functions of the plant and to teleology. Function does not concern us except in so far as it is found to enter as a causal factor into the process of development. Similarly, until purpose can be shown to be effective as a causal factor it is merely an unfortunate expression for the result attained.

Let me remind you, also, that the individual plant, whether it be unicellular, cœnocytic, or multicellular, may behave as a whole at all stages of its development. We see this, for instance, in the germination of CEdogonium, in the germination and subsequent strengthening of the basal region in Fucus or Laminaria, in the moss-plant or fern-plant, or in a dicotyledonous tree. A system of relations is evident in the plant, expressed in the polarity and the mutual influences of the main axis and lateral branches, as well as in the influences exerted on the basal region by the distant growing parts. We thus recognise, in its most general form, the correlation of parts, a concept of proved value in botany.

To some the expression of the observed facts in this way may appear perilously mystical. I do not think so myself. It is true that the nature of the specific substance and of the system of relations is unknown to us, but it is regarded as a subject for scientific inquiry and further explanation. To recognise fully the complexity of the substance of the plant is not, however, a step towards neo-vitalism, but is perhaps our best safeguard against the dangers of this.

The wholeness of the individual, together with important phenomena of regeneration, has suggested the conclusion that something other than physicochemical or mechanical laws are concerned in the development of the organism. To this something Driesch aprlies the name entelechy. Without discussing the vitalistic philosophy of the organism, or other modern phases of philosophic thought that treat life as an entity, it seems worth while to point out that they are based mainly on the consideration of animal development. It would be interesting to inquire into the difficulties that are met with in applying such views to plants, where regeneration in one form or another is the rule rather than the exception, and often does not lead to restitution of the individual. Causal morphology can recognise phenomena of development and of the individual, which are at present beyond physico-chemical explanation, and try to attack them by any methods of investigation that seem practicable, without begging the main question at the outset and then proceeding deductively. To assume any special inner director of development, be it entelechy or vital force, is to cut the knot that may ultimately be untied.

The previous experience of botany in the time of nature-philosophy may well make us cautious of solving our difficulties by the help of any new biological philosophy. On the other hand, co-operation between biology and philosophic thought is highly desirable. In this connection I should like to refer to an idea contained in Prof. Alexander's paper on the basis of realism. He suggests that there is only one matrix from which all qualities arise, and that (without introducing any fresh stuff of existence) the secondary qualities, life, and at a still higher level, mind, emerge by some grouping of the elements within the matrix. The development of this idea as it applies to life would appear to offer a real point of contact between inductive biological work and philosophy.

To return to our plant, its development, with increase in size and progressive complexity of external form and internal structure, must be considered. The NO. 2400, VOL. 96] power of continued development possessed by most plants and wanting in most animals makes comparison between the two kingdoms difficult. That there is no fundamental difference between the continued and the definitely limited types of embryogeny is, however, shown by plants themselves. The bryophyte sporogonium is a clear example of the latter, while the fern sporophyte is one of many examples of the former. A difference less commonly emphasised is that in the sporogonium (as in the higher animals) the later stages of development proceed by transformation of the whole of the embryo into the mature or adult condition; in the fern-plant the apical development results in successive additions of regions which then attain their mature structure by transformation of the meristematic tissue.

These distinctions are of some importance in considering the generalisatinn originally founded on animal development and known as the biogenetic law. 'That "the ontogeny is a concise and compressed recapitulation of the phylogeny" is essentially a phyletic conception. It has been more or less criticised and challenged by some distinguished zoologists, and has always been difficult to apply to plants. If we avoid being prejudiced by zoological theory and results, we do not find that the characters of the embryos of plants have given the key to doubtful questions of phylogeny. What help do they give us, for instance, in the algæ or the vascular cryptogams? The extension of the idea of recapitulation to the successively formed regions of the seedling plant requires critical examination; if admitted, it is at any rate something different from what the zoologist usually means by this. The facts-as shown, for instance, in a young fern-plant-are most interesting, but can perhaps be better looked at in another way. Development is accompanied by an increase in size of the successively formed leaves and portions of stem, and the process is often cumulative, going on more and more rapidly as the means increase until the adult proportions are attained. The same specific system of relations may thus find different expression in the developing plant as constructive materials accumulate. I do not want to imply that the question is merely a quantitative one; quality of material may be involved, or the explanation may lie still deeper. The point is that the progression is not a necessary one due to some recapitulative memory.

There are some other classes of facts, clearly cognate to normal individual development, that seem to require the causal explanation. I may mention three:-(I) Vegetatively produced plants (from bulbils, gemmæ, etc.) tend in their development to pass through stages in elaboration similar to young plants developing from a spore or zygote. The similarities are more striking the smaller the portion of material from which a start is made. (2) Branches may repeat the stages in ontogeny more or less completely also in relation to differences in the nutritive conditions. (3) In the course of continued development there may be a return to the simpler form and structure passed through on the way to the more complex. These cases of parallels to, or reversals of, the normal ontogenetic sequence suggest explanation on causal lines, but are difficulties in the way of phyletic recapitulation; the first two cases can be included under this, while the third seems definitely antagonistic. On the whole, it may be said that recapitulation cannot be accepted for plants without further evidence, and that preliminary inquiry disposes us to seek a deeper and more fruitful method of explaining the facts of development.

The development of most plant-individuals starts from a single cell, and when we compare mature 
forms of various grades of complexity the unicellular condition is also our usual starting-point. What is not so generally recognised or emphasised is the importance of the flament as the primitive construction-form of most plants. I do not use the word primitive in a phyletic sense, nor in the sense of an ideal form, but to indicate a real stage in independent progressions underlying many homologies of organisation. I cannot develop this fully here, but wide comparison of independent lines of advance suggests that the main types of progress in complexity of the plant-body have involved the elaboration of the single filament with apical growth and with subordinated "branches." It is generally recognised that various groups of algæe show how a solid multicellular axis may come about, not only by the further partition of the segments of the apical cell, but by the congenital cortication of a central filament or the congenital condensation of the subordinated "branches" on to the central axis. The algæ further show the change from the dome-shaped apical cell of a filament to the sunken initial cell with two, three, or four sides. The central filament then only appears, if at all, as a subsequent differentiation in the tissue, and the segments serially cut off from the apical cell may or may not bear projecting hair-shoots or "leaves." The algæ thus attain in independent lines a construction corresponding to that of the plant in liverworts and mosses. In the various parallel series of Bryophyta the filament is not only more or less evident in the ontogeny, but may be regarded as the form underlying both thallus and shoot, between which on this view there is no fundamental distinction. The sporogonium also can be readily regarded as an elaborated filament. While the same interpretation of the fernprothallus will readily be granted, to think of the fern-plant as the equivalent of an elaborated filament may appear far-fetched. So far from this being the case, I believe that it will be found helpful in understanding the essential morphology of the shoot. In a number of vascular cryptogams and seed-plants, there is actually a filamentous juvenile stage, the suspensor, while the growth by a single apical cell is essentially the same in the fern as in the moss and some algæ.

There follows from this a natural explanation of the growth by a single initial cell so commonly found in plants. The apical cell appears to be the one part of the massive plant-body (for instance, of Laurencia, a moss, or a fern) that persists as a filament; it is a filament one cell long. It may be replaced by a group of initial cells, as we see in some algæ, liverworts, and Pteridophyta, and this leads naturally to the small celled meristems found in most Gymnosperms and Angiosperms. The filamentous condition is then wholly lost, though the system of relations and especially the polarity is maintained throughout all the changes in the apical meristem.

I feel confirmed in regarding the construction of the sporophyte in this fashion by the fact that it fits naturally with the conclusions resulting from the masterly comparative treatment of the embryology of the vascular cryptogams by Prof. Bower. These are (I) the primary importance of the longitudinal axis of the shoot, the position of the first root and the foot being variable; (2) the constancy of the position of the stem-apex near the centre of the epibasal half of the embryo; (3) the probability that embryos without suspensors have been derived from forms with suspensors, without any example of the converse change. These and other related facts seem to find their morphological explanation in the shoot of the sporophyte being the result of the elaboration of a filament.

NO. 2400, VOL. 96]
The Construction of the Shoot.

The view to which we are thus led is that the uniaxial shoot is a complex whole, equivalent to the axial filament together with its congenitally associated subordinated "branches." This applies to the multicellular plant-bodies found in various independent lines of alga and Bryophyta, whether they have definite projecting appendages of the nature of leaves or not. The discarding of the distinction between thallus and shoot, which in practice has proved an unsatisfactory one, is no great loss. Even taking the word in the narrower sense of a stem with distinct leaves, the shoots in algæ, liverworts, and mosses, though admittedly independent developments, exhibit an essential correspondence amounting to a homology of organisation. The resemblances are not analogies, for it is doubtful whether the "leaves" in the different cases correspond in function. The comparison of the shoot of the sporophyte of a vascular cryptogam with, for example, the shoot of the moss seems equally justifiable. It is only forbidden by strict phyletic morphology, which for our purpose has no jurisdiction. The general agreement as regards the leaf-arrangement between the ferns and the Bryophyta suggests that similar laws will be found to hold in the shoot of both gametophyte and sporophyte. Apart from plagiotropic shoots, there is a constructionally dorsiventral type of fern-rhizome. The leaves of this alternate as in the leafy liverworts, while the radial type of fern corresponds to the moss-shoot. It is significant that the early leaves of radially constructed ferns usually exhibit a divergence of $\frac{1}{3}$ in the seedling, passing higher up the stem into more complicated arrangements, and the same is the case in mosses. I must not enter into questions of phyllotaxy, but may remark on the hopefulness of attacking it from the study of the simpler shoots of algæ and Bryophyta rather than, as has usually been done, beginning with the flowering plants.

In some ferns (the striking example being Ceratopteris) the relation between the segmentation of the apical cell and leaf-production is as definite as in the moss, each segment giving rise to a leaf. This may hold more widely for ferns than is at present demonstrated, and the question deserves thorough reinvestigation to ascertain the facts independently of any theoretical views. That the coincidence of the segmentation of the shoot expressed by the leafarrangement and the segmentation of an apical cell is not a necessary one is, however, clearly shown in other ferns, and is obvious in the case of shoots with a small-celled meristem. The two segmentations appear to be determined by some deeper system of relations, which may also be manifested in a cœnocytic plant-body.

In the complication of the uniaxial shoot introduced by branching also there seems to be an advantage in a wide area of comparison. The question most often discussed concerns dichotomous and monopodial branching. If the details of development are to be taken into consideration, the term "dichotomy" has usually been very loosely applied. Apparent dichotomy, the continuation of one shoot by two equally strong ones, is fairly common. But in most cases investigated in detail the branching seems to be really monopodial and the forking due to the equally strong development of a lateral branch close to the main apex, not to the division of the latter. In plants growing by a single initial cell almost the only case of strict dichotomy known is the classic one of Dictyota. The branching of the ferns has been the subject of numerous investigations, but there is a great lack of developmental data. Usually the branches stand in some definite relation to the leaves 
of the shoot, behind, to one side, or on the leaf-base, itself, the most interesting but least common case being when the branch is in an axillary position. When the mature shoot only is considered, it is possible to argue for the derivation of monopodial branching from dichotomy or the converse. Even the facts obtainable from the mature plant, however, point to the dichotomous branching being a modification of the monopodial, the opposite view appearing to land us in difficulties regarding the morphology of the main shoot. It is unlikely that a dichotomy involving the division of the apical cell occurs in the fern-shoot, and comparison with the Bryophyta confirms the suspicion that the cases of dichotomy are only apparent.

In considering the construction of the shoot we are at present limited to comparison of the normal structure and development. The system of relations in the shoot of the fern, affecting in the first place the distribution of the leaves and secondly that of the branches, appears, however, to be of the same nature as in the independently evolved shoots of Bryophyta and algæ. A morphological analysis based on the simpler examples may lead on to the experimental investigation of the common construction. The relation that exists between the general construction and the vascular anatomy offers a special and more immediately hopeful problem. Here also, in considering the fern, we are assisted by homologies of organisation in other vascular cryptogams and in the more complex Bryophyta, though the algæ are of little help.

In few departments of botany has our knowledge increased so greatly and become so accurate as in that of vascular anatomy. The definiteness of the structures concerned and the fact that they have been almost as readily studied in fossil as in living plants has led to this. Not less important have been the clear concepts first of the bundle system and later of the stele under which the wealth of fact has been brought. Great progress has been made under the influence of phyletic morphology, and anatomy has adopted further conventions of its own and tended to treat the vascular system as if it had an almost independent existence in the plant. The chief method employed has been the comparative study of the mature regions, of necessity in the fossils and by choice in the case of existing plants. I do not, of course, mean to say that we are ignorant of the development of the vascular system, but the variety in it has not been adequately studied in the light of apical development. A gap in our knowledge usually comes between the apical meristem itself and the region with a developed vascular system. It is in this intermediate region that the real differentiation takes place, and the arrangement of the first vascular tracts is then modified by unequal extension of the various parts. The apical differentiation requires separate study for each grade of complexity of the vascular system, even in the same plant.

If we look at the vascular system, not as if it had an independent existence or from the phyletic point of view, but as a differentiation taking place within the body of the individual plant, we can inquire as to the causal factors in the process. A deeper insight into the nature of the stele may be obtained by regarding it as the resultant of a number of factors, as part of the manifestation of the system of relations in development. The first step towards this is the critical consideration of normal developing plants, but so long as the causal influences in the developing substance of a plant remain unchanged the resulting vascular structure will remain constant. Our hope of advance lies in the study of cases where these influences are modified. Herein lies the value of abnormalities, of natural experiments, and the results of experimental interference. Possible influences that have at various times been suggested are functional stimuli, the inductive influence of the older pre-formed parts on the developing region, and formative stimuli of unknown nature proceeding from the developing region. The functional stimuli do not come into play at the time of laying down the vascular tracts, though they may have importance in their maintenance later; the inductive influence of the anatomy of older regions is excluded in the first differentiation of the vascular system in an embryo; we are thus led to attach special importance to the detection of the action of formative stimuli proceeding from the young developing primordia. We have further to talse external stimuli into account, though these must act by influencing the internal system of relations.

Time will not permit of reference to the scattered literature bearing on this subject, but it may make the reality of such formative stimuli a little clearer if I refer to some examples that have turned up in the course of my morphological work. In the case of the shoot, formative influences must act in the small apical region where we have the meristematic growing point with the primordia of the leaves. There is a presumption in favour of some sort of segmental construction of the meristem in relation to the leaves, whether this coincides with the cell-segmentation or not, and such a segmental construction is reflected in the vascular system. Can we in the first place distinguish any parts played by influences from the stemapex and the developing leaves respectively? Unfortunately we know little or nothing of the anatomical relations in the rare cases of adventitious leafformation. We get a little insight into the respective influences of leaf and axis, however, when we compare shoots with well-developed leaves and those without leaves or with greatly reduced leaves; this may be done between distinct plants or between different regions of the same plant. It seems to emerge from such comparisons that, as regards the xylem at least, a central strand may be independent of influences from the leaves, while the latter may not only determine the leaf-traces connecting with the central strand, but may influence the periphery of this; the result is a cylinder of outer xylem continuous with the leaf-traces. This general conception is borne out by widely different plants, the correspondences between which are homologies of organisation. I may instance the stele of the Polytrichacez as analysed by Mr. and Mrs. Tansley, the stele of the rhizome and aerial shoots of the Psilotaceæ, of the Lycopods with larger or smaller leaves, and the stele of the ferns at various ages of the plant. The shoot of Isoetes, which is of the Lycopod type, but has relatively large leaves, shows the composite nature of the stelar xylem particularly clearly, and also suggests how the component influences are at work in the meristematic region of the stem bringing about the resultant structure.

Owing to the small size of the shoot-apex, it is difficult to induce deviations from the normal to show the respective parts played by the central axis and by the influences from the leaf-primordia. The reality of influences proceeding backwards from developing structures is better brought out when they may be present or absent, and for this lateral buds are of special interest. As a rule, the primary development of buds has proceeded far enough to determine the connecting vascular tracts, but in the case of the dormant axillary apices of Botrychium no influence has been exercised on the vascular structure of the main shoot. When, however, such a lateral apex is called into activity, it not only forms its own vascular system as it develops, but exerts an influence backwards through permanent tissue leading to the pro- 
duction of a "branch-trace" connecting with the adaxial face of the subtending leaf-trace. In Helminthostachys a similar connection is established with the stele of the main stem, and the influence may extend to the whole periphery of the main stele, inducing a continued or secondary production of xylem both behind and before the place of insertion of the branch.

These constructions were, in a sense, called forth by experimental interference, since they occurred in plants the normal apical growth of which had been arrested. Plants of Osmunda are normally unbranched, and no indication of dormant lateral apices has ever been detected. I tried on young plants of Osmunda regalis the experiment of injuring or destroying the apex of the shoot, with the result that in a number of them branching was induced. The vascular relations exhibited considerable variety, but in some clear cases the branch was developed in an axillary position with regard to a leaf-primordium, and its vascular connection was with the adaxial face of the subtending trace in the same fashion as in Botrychium and in some species of Zygopteris. The disturbance of the normal growth had apparently brought out (in more or less irregular form) the system of relations governing the position of development of lateral branches. The result showed the correspondence with what is the normal condition in some Zygopterideæ. It has been said from the phyletic side, and on the whole rightly, that experiment cannot reconstruct history. In the light of Dr. Kidston and Professor Gwynne-Vaughan's conclusions as to the derivation of the Osmundaceæ from a Zygopterid ancestry, this induced branching of Osmunda might almost be cited as a partial exception to the statement.

These examples will suffice to indicate the justification for a change of attitude in the study of the vascular system. Looked at in this light, the stele appears not as a characteristic thing inherited as such, but as a complex resultant. The problem gains in interest, new questions (which are different from, though not antagonistic to, phyletic problems) can be put as to stelar structure, leaf-trace structure, the venation of leaves, etc. We see this if we glance at the progression in stelar structure that accompanies the development of the young fern. The phyletic explanation has been recapitulation. We have found reason to criticise the adequacy of this as applied to external form, and the same line of criticism applies to the stelar progression. In this also the early stages may be hurried over or absent, and, still more significant, the early type of stelar structure may recur, when the shoot has fallen upon evil days and approximated in size of stem and leaf-form to the seedling condition. From such points of view the vascular system offers problems in general or causal morphology not merely of great interest, but with some possibility of solution. Thus the parallel progressions from protostely to a medullated monostele, and from protostely to solenostely and dictyostely may be treated as problems in the expansion and condensation of a stelar structure, which is itself the resultant of a system of influences. Such parallel progressions are before us within the ferns and also in other groups of vascular cryptogams.

(Alternation of generations, the morphology of the seed, and the morphology of the embryo of seed-plants were then considered from the viewpoint of causal morphology.)

\section{Conclusion.}

I have touched on a number of large questions, any one of which demanded separate treatment. My concern has not, however, been with them individually, but as cognate problems justifying the deliberate adop- tion of a causal explanation as the aim of morphological work. I have confined myself to problems bearing on the development and self-construction of the individual, and tried to treat them so as to illustrate the causal attitude and possible lines of attack. Preliminary speculations on the questions considered can at best contain a germ of truth, and must be subsequently adjusted in the light of further facts. I have discussed these questions rather than the smaller modifications in individual development shown in metamorphosis, partly because the latter have of late years been treated from a causal point of view, and partly because I wished to consider questions that immediately affect us as working morphologists.

Did time allow, we should naturally be led to recognise the same change of attitude in biological science toward the problems of the origin of new forms. Questions of bud-variation and mutation are clearly akin to some of those considered, and the whole subject of genetics is a special attempt at a causal explanation of form and structure and the resulting functions. Close co-operation between the morphological analysis of the plant and the genetic analysis attained by the study of hybridisation is most desirable. It is especially desirable that both should deal with structure as well as with form, and in the light of individual development.

The causal factors which have determined and guided evolution can be naturally regarded as an extension of the same line of inquiry. The Darwinian theory, and especially the exposition of the principle of natural selection, was the greatest contribution ever made to the causal explanation of the organic world. Strangely enough, it led to a period of morphological work in which the causal aim was almost lost sight of. Why evolution has taken place in certain directions and not in others is a problem to the solution of which causal morphology will contribute. The probability of orthogenesis, both in the animal and vegetable kingdoms, is again coming into prominence, however it is to be explained. When we consider the renewed activity in this field it is well to remember that, just as is the case with causal morphological work, we are picking up a broken thread in the botanical web. Lastly, as if summing up all our difficulties in one, we have the problem of adaptation. In attacking it we must realise that use and purpose have often been assumed rather than proved. We may look to scientific ecological work to help us to estimate the usefulness or the selection value of various characters of the plant. On the other hand, causal morphology may throw light on whether the "adaptation" has not, in some cases at least, arisen before there was a "use" for it. The hopeful sign in the recent study of these greater morphological problems is that the difficulties are being more intensely realised, and that rapid solutions are justly suspect. The more the causal attitude is adopted in ordinary morphological work, the more hope there is of these larger questions being inductively studied rather than argued about.

The causal aim is essentially different from the historical one, but there is no opposition between causal and phyletic morphology. They are rather mutually helpful, for there has been an evolution, not of mature plants, but of specific substances exhibiting development. A deeper insight into the nature of ontogeny is thus bound to be of assistance to phyletic morphology, while the tested results of phyletic work afford most valuable guidance in general causal morphology, though this cannot accept any limitation to single lines of descent in its comparisons.

I have tried to bring before you the possibilities of causal morphology partly because the same attention 
has never been given to it in this country as to other branches of botany, and partly because if morphology be conceived in this broader spirit it need not be said that it has no practical bearing. I should not regard it as a serious disability were the study of purely scientific interest only, but this is not the case. When, if ever, we penetrate into the secrets of organisation so far as to be able to modify the organism at will (and genetics has advanced in this direction), the practical possibilities become incalculable.

Probably all of us have reflected on what changes the war may bring to botanical work. It is impossible to forecast this, but I should like to emphasise what my predecessor said in his address last year as to pure science beirg the root from which applied science must spring. Though results may seem far off, we must not slacken, but redouble our efforts towards the solution of the fundamental problems of the organism. This can be done without any antagonism between pure and applied botany; indeed, there is every advantage in conducting investigations on plants of economic importance. It would be well if every botanist made himself really familiar with some limited portion of applied botany, so as to be able to give useful assistance and advice at need. The stimulus to investigation would amply repay the time required. Even in continuing to devote ourselves to pure botany we cannot afford to waste time and energy in purposeless work. It is written in "Alice in Wonderland" that "no wise fish goes anywhere without a porpoise," and this might hang as a text in every research laboratory.

A plant is a very mysterious and wonderful thing, and our business as botanists is to try to understand and explain it as a whole and to avoid being bound by any conventional views of the moment. We have to think of the plant as at once a physico-chemical mechanism and as a living being; to avoid either treating it as something essentially different from nonliving matter or forcibly explaining it by the physics and chemistry of to-day. It is an advantage of the study of causal morphology that it requires us to keep the line between these two crudities, a line that may some day lead us to a causal explanation of the developing plant and the beginnings of a single science of botany.

\section{UNIVERSITY AND EDUCATIONAL} INTELLIGENCE.

LoNDON.--The course of six advanced lectures on "Stelar Anatomy in Angiosperms," by Miss E. N. Thomas, University reader in botany, announced to begin at Bedford College on November $I$, has been postponed until January next.

OxFord.-On October 26 the honorary degree of D.Sc. was conferred on Mr. Guy A. K. Marshall, director of the Imperial Bureau of Entomology. The Public Orator, in presenting Mr. Marshall, spoke of the great services rendered by him to scientific entomology during his residence in South Africa, mentioning in especial his work on Coleoptera and Lepidoptera. He also referred in appreciative terms to the valuable researches being carried on under Mr. Marshall's direction in the recently established Imperial Bureau of Entomology.

In moving Congregation for the grant of a pension to Mr. Henry Walters, assistant for forty-five years in the Clarendon Laboratory, Prof. E. B. Elliott made a sympathetic reference to the retirement of Prof. R. B. Clifton, after fifty years of devoted service to the department of physics in the University.

NO. 2400 , VOL. 96]
Prof. A. H. Whire has resigned the chair of pathology in the school of the Royal College of Surgeons in Ireland, after a tenure of seventeen years.

Dr. Michell Clarke will deliver the Bradshaw lecture at the Royal College of Physicians of London on November 2, taking as his subject "Nervous Affections of the Sixth and Seventh Decades of Life"; the FitzPatrick lectures will be given on November 4 and 9, by Dr. W. H. R. Rivers, on "Medicine, Magic, and Religion"; and the Goulstonian lectures by Dr. Gordon Holmes, on November 16,18 , and 23 , on "Acute Spinal Lesions, with Special Reference to those of Warfare."

THE arrangements announced in the calendar of the University of Leeds for the current session follow the same general lines of previous years. They are subject to modification in the event of rearrangements being necessitated by circumstances arising in connection with the war. As has become usual in our more modern universities, great prominence is given to the work in applied science and technology. Students may graduate in science and take for their principal subject one of the following branches:--Mechanical, civil, electrical, mining, or gas engineering; fuel and metallurgy; agriculture; colour chemistry and dyeing; and the chemistry of leather manufacture. Similarly the needs of commerce have been recognised. Students in the department of economics and commerce may take a three years' course for the degree of Bachelor of Commerce, a two years' course for the diploma in commerce, or a one year's course for the diploma in social organisation and public service. Side by side with these courses, designed to meet the special needs of the area served by the University, are others covering completely the requirements of students in arts, science, law, medicine, and so on. Evening classes in many subjects have been arranged and university extension lectures are provided in a miscellany of subjects.

\section{SOCIETIES AND ACADEMIES.}

\section{MANChester.}

Literary and Philosophical Society, October 5--Prof. S. J. Hickson, president, in the chair.-W. J. Perry : The relationship between the geographical distributions of megalithic monuments and ancient mines. The fact that the distribution of megalithic monuments coincides with the centres of ancient mining and coast-lines adjoining pearl-shell fisheries suggests a genetic relationship between the two kinds of activities. The megalithic monuments that have been found in various places beyond the limits of the ancient East are the tombs and temples of the mining camps of the settlements engaged in exploiting gold, silver, copper, tin, and precious stones. The search for pearl-shell led the Phœnicians, and their pupils, from the Red Sea and the Persian Gulf to India and Ceylon, to Indonesia and Japan, to the islands of the Pacific, and eventually to America; and in every spot where they settled to work the mines or collect pearl-shell they planted the germs of the Old World civilisation.

\section{PARIS.}

Academy of Sciences, October x8.-M. Ed. Perrier in the chair.-The President announced the deaths of Gaston Vasseur and Henri Fabre.-Louis Fabry and Henri Blondel : The identity of the new Comas Sola planet with I93 Ambrosie. This planet proves to be identical with that discovered in 1879 by M. Coggia.J. Dejust : The use of a Venturi tube for the direct 